\title{
Duration and resolution effects on visual persistence (positive afterimages)
}

\author{
GERALD M. LONG \\ Villanova University, Villanova, Pennsylvania
}

\begin{abstract}
The effects of varying target duration and target size on the duration of visual persistence were assessed in a probe-matching task for both foveal and peripheral targets presented against scotopic, mesopic, and photopic background fields. Persistence was found to increase with increasing target duration and increasing target size under all conditions of retinal location and background field. Results are discussed in terms of an early sensory locus to the persistence assessed by the task employed. The possible bases for discrepancies with other work are proposed in terms of differing processes within the visual system that may be involved by the different persistence tasks favored by various investigators.
\end{abstract}

Despite impressive empirical effort, there is at present no generally accepted model of visual persistence. Within the past decade, persistence effects have been attributed to peripheral processes such as sluggish photoreceptor functioning (Sakitt, 1976; Sakitt \& Long, 1978, 1979a, $1979 \mathrm{~b})$, to the temporal response characteristics of the transient and sustained channels (Bowling \& Lovegrove, 1980; Meyer \& Maguire, 1977), to cognitive processes of information extraction and storage (Coltheart, 1980; DiLollo, 1980), and to other explanations (see Coltheart, 1980). Moreover, for each of these classes of explanation, some degree of underlying empirical support can be found in the myriad of contradictory empirical findings in the literature. Visual persistence effects have been reported to be positively related to target energy (e.g., Long, 1985; Long \& Sakitt, 1980; Sakitt, 1976), negatively related to target energy (e.g., Bowen, Pola, \& Matin, 1974; DiLollo, 1977), and independent of target energy (e.g., Adelson \& Jonides, 1980). The effects of other stimulus manipulations on persistence are equally contradictory. Such glaring empirical discrepancies are almost certainly due to a range of factors, including differing tasks and stimulus conditions which may have served to involve different or additional processes in the visual system, but they nevertheless render this area of research most resistant to any simple or unambiguous integration.

The present research represents an attempt to apply a psychophysical approach to the study of the persistence effects revealed by a popular persistence task. There were several factors that dictated this type of careful parametric approach. First, there has been some claim that previous work in this area has often varied stimulus conditions over minimal ranges or has employed atypical stimulus values (Adelson \& Jonides, 1980; Bowling \& Lovegrove, 1982;

This research was supported by Grant 1 R01 EY04485-01A1 from the National Eye Institute. The author would also like to express his appreciation to Brian Lyman for his invaluable aid throughout this research. Please address all reprint requests to G. M. Long, Department of Psychology, Villanova University, Villanova, PA 19085.
Coltheart, 1980; DiLollo, 1984). The present work employs a wide range of target and background conditions that avoid this criticism. Second, the particular persistence task chosen has been used by several previous investigators and appears to reflect visible persistence in its most basic form: the continued visible impression of a brief target after its physical termination. On each trial, subjects are asked to indicate whether all trace of a brief target has ceased by the time a probe stimulus is presented. Other persistence tasks often involve less direct assessment procedures, which makes the comparison of performance across tasks very difficult. Finally, this work represents a continuation of a line of investigation by the author and his colleagues that has sought to establish the sensory contribution to persistence. Such a view, which places the source of persistence very early in the visual system, requires strong effects of particular stimulus manipulations. The present work focuses on these predictions.

\section{METHOD}

\section{Subjects}

The author and a male research assistant served as observers in about 20 sessions each over a 2-month period. Each session lasted between 45-60 $\mathrm{min}$, and the observer dark adapted monocularly for $40 \mathrm{~min}$ prior to each session.

\section{Apparatus and Stimuli \\ A four-projector arrangement with high-intensity Kodak Ektagraphic (AF-1) projectors was used to present the targets, probe, and background field on a $3.5^{\circ} \times 5.0^{\circ}$ opal glass rear-view screen. Two projectors, with a millisecond shutter (Gerbrands Model 61166) mounted directly on each lens' barrel, presented the two components of the target stimu- lus on each trial. These two luminous $1^{\circ} \times 1^{\circ}$ squares were separated by a variable amount. These squares were presented simultaneously for a duration set by the experimenter between 25 and $200 \mathrm{msec}$ (see be- low). The observer reported whether the dark gap between rectangles was still present when the $20-\mathrm{msec}$ probe light occurred. This probe was a $12.4^{\prime}$ dot positioned on a constant dark background $3^{\circ}$ to the right of the target gap. Its luminance was constant at $.3 \mathrm{fL}\left(1.0 \mathrm{~cd} / \mathrm{m}^{2}\right)$. \\ The durations of the target and probe were controlled by a six-channel Gerbrands timer/driver (Model 300-6T). Target and background lu-}


minances were controlled by positioning filters (Kodak Wratten No. 96) of varying neutral densities in the various projector channels. Great care was taken to ensure that only positive afterimages of the targets were produced by the luminance conditions chosen. Retinal location was varied by having the fiber optics fixation points in the center of the screen (on which the targets were presented) or $7^{\circ}$ to the left of screen center.

\section{Procedure}

The probe-matching task of visual persistence was chosen because of its simplicity, even for naive observers, and because of the rapidity of data collection that it permits. On each trial, the observer was instructed simply to respond "early" if any trace of the target gap was still visible when the probe was presented or "late" if all trace of the target gap had completely disappeared by probe onset. By systematically varying the interstimulus interval (ISI) between target offset and probe onset, the experimenter could estimate the total duration of target visibility for any given set of stimulus conditions. The ISI was varied by the experimenter in a double-staircase procedure in which the ISI was decreased in 20-msec steps from an initial high value (descending series) or increased in 20-msec steps from an initial low value (ascending series). In either type of series, four response reversals between "early" and "late" were required before that series was completed. This identical procedure has been employed previously (Long, 1985).

A gap-detection target was used for several reasons in this work. Most importantly, one manipulation of the present work involved varying resolution requirements on the persistence task, and this was easily accomplished by varying gap width. Second, observers report greater confidence in their responses concerning a fading target image when a resolution requirement is involved rather than only target detection.

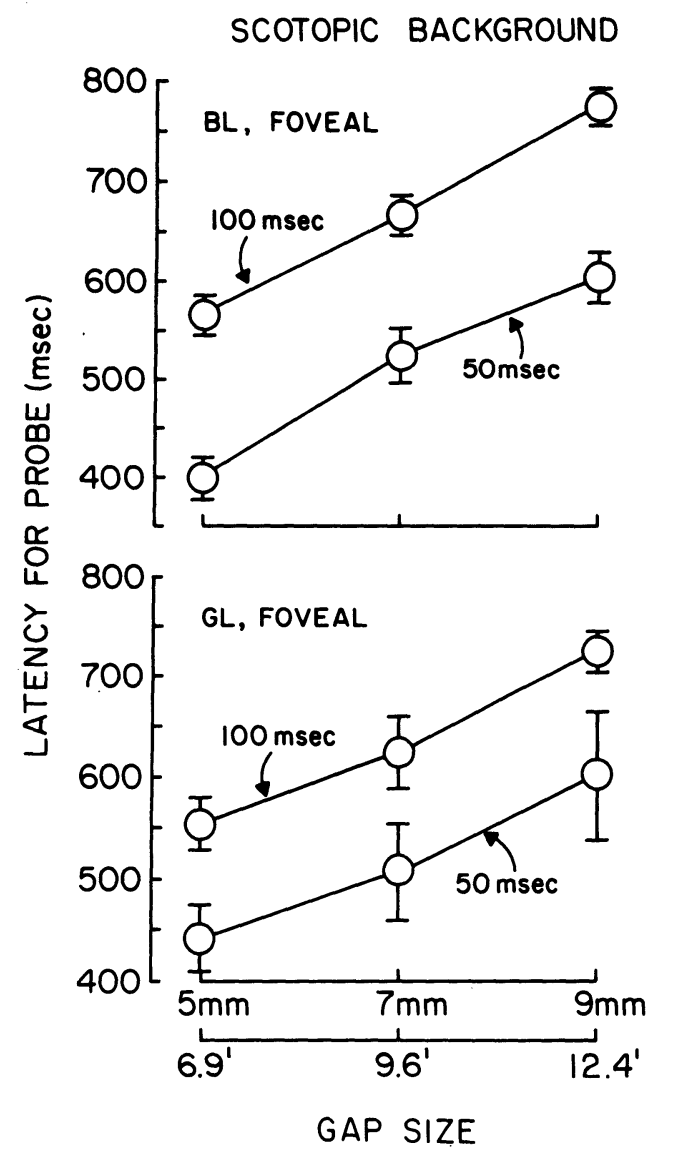

Figure 1. Mean persistence estimates for two observers as a function of gap size and target duration. Targets were presented foveally against a scotopic background field. The brackets around each point depict two standard errors above and below that value.

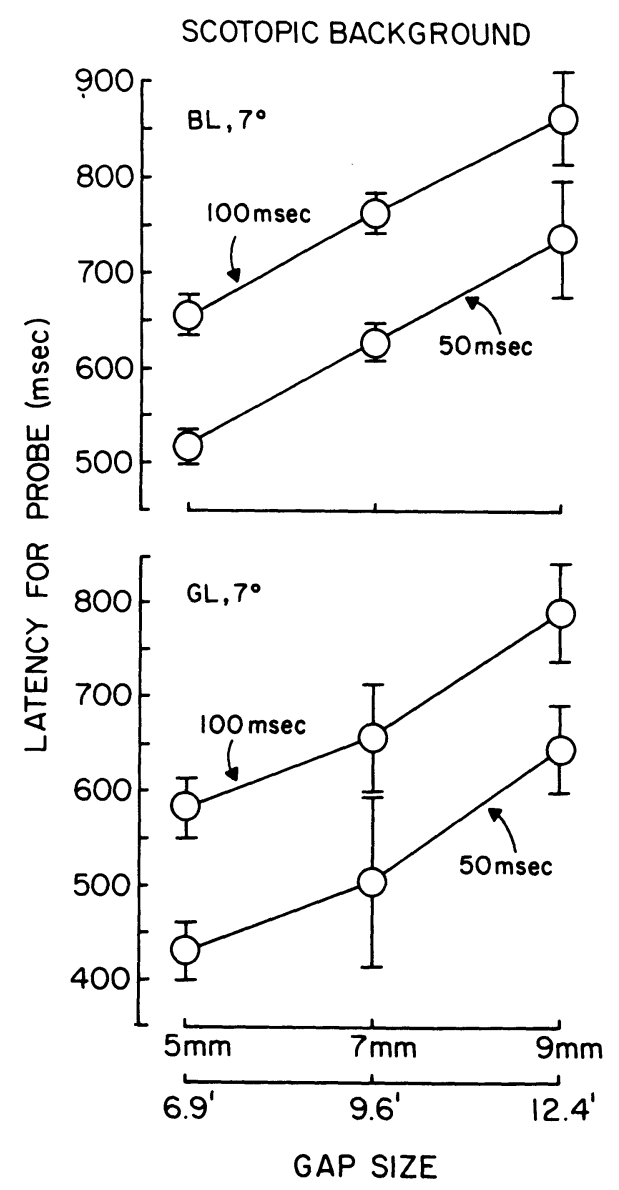

Figure 2. Mean persistence estimates for two observers as a function of gap size and target duration. Targets were presented $7^{\circ}$ from fixation and on a scotopic background field.

Several years ago, Brindley $(1962,1963)$, in his research with classic negative afterimages, used luminous targets with central gaps, the presence of which observers were to attend to in the fading afterimage. The present work simply extended the Brindley task to the assessment of a much briefer form of persistence.

\section{RESULTS}

Figure 1 presents the mean persistence estimates (probe latencies) for constant-luminance targets of $1.0 \mathrm{~cd} / \mathrm{m}^{2}$ presented foveally on a scotopic background field of $.03 \mathrm{~cd} / \mathrm{m}^{2}$. The two portions of the figure contain the results for the two dark-adapted observers as a function of gap size and target duration. Each point on the curves is based on four double-staircase runs collected over two sessions.

It is clear from the figure that visible persistence is positively related to target size and to target duration. Figure 2 presents the corresponding results for the identical stimuli presented $7^{\circ}$ from fixation. The same pattern of results is evident. Figures 3 and 4 present the persistence estimates obtained with a high photopic background field of $342 \mathrm{~cd} / \mathrm{m}^{2}$ and target luminance of $514 \mathrm{~cd} / \mathrm{m}^{2}$ that clearly exceed the levels used in most persistence studies that employ either CRTs or commercially available tachistoscopes. Such a high background level also exceeds that 


\section{HIGH PHOTOPIC BACKGROUND}

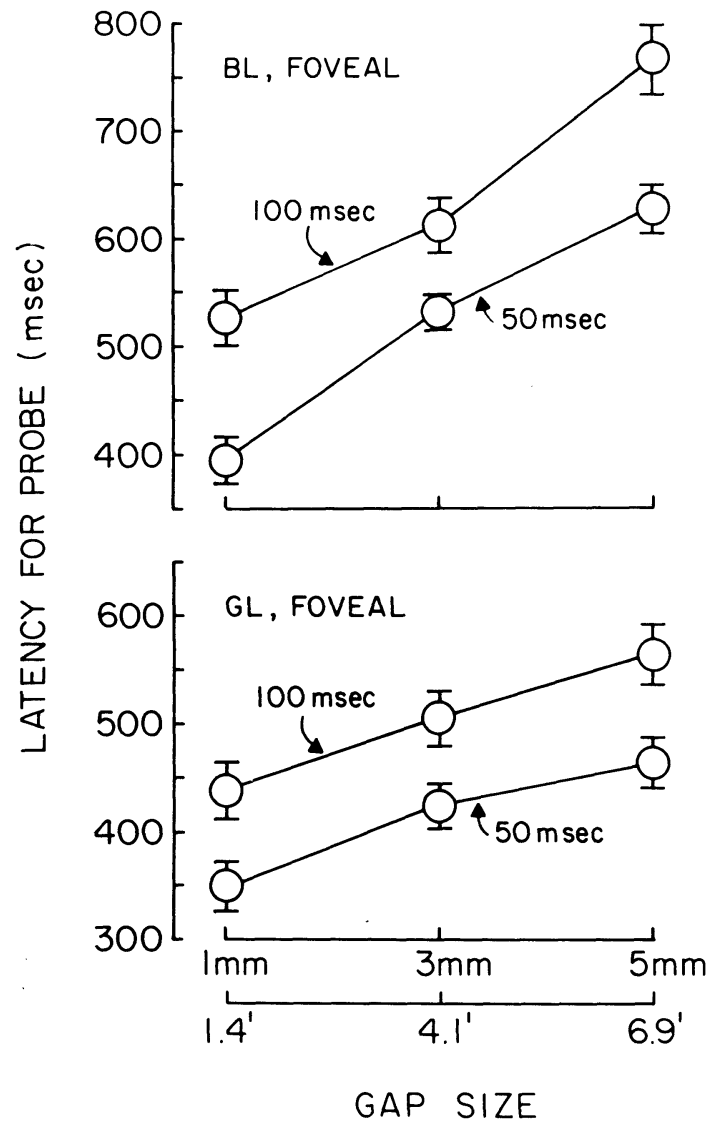

Figure 3. Mean persistence estimates for two observers as a function of gap size and target duration. Targets were presented foveally against a high photopic background field.

necessary for rod saturation (Aguilar \& Stiles, 1954) and thereby restricts the task to the cone receptor system. The pattern of results is the same for both the foveal (Figure 3) and peripheral (Figure 4) conditions. Finally, entirely comparable results (not shown) of foveal and peripheral target presentation were also obtained with an intermediate photopic background level $\left(3.4 \mathrm{~cd} / \mathrm{m}^{2}\right)$ and $34.3 \mathrm{~cd} / \mathrm{m}^{2}$ target luminance.

Given the widely divergent claims for target duration effects that have been made in the persistence literature, I decided to take a more fine-tuned approach to such effects in the present work. Hence, at a given background level, and with a constant target luminance and gap width, target duration was varied (randomly) over the following values: $25,50,75,100,150$, and $200 \mathrm{msec}$.

Figure 5 presents the results for two observers under photopic background and foveal viewing conditions with a $12.4^{\prime}$ gap $(9.0 \mathrm{~mm})$ and a constant $34.3 \mathrm{~cd} / \mathrm{m}^{2}$ target luminance. For each observer, a strong monotonically increasing function between probe latency and target duration is obtained. The analogous functions (not shown) relating target duration and visual persistence were also determined for each subject under scotopic background conditions $\left(.03 \mathrm{~cd} / \mathrm{m}^{2}\right)$ and with a peripheral $\left(7^{\circ}\right)$ target location. In each case, a clear positive relationship between target duration and target persistence is evidenced.

\section{DISCUSSION}

The results presented in Figures 1-5 reveal a very straightforward nature to the persistence effects assessed by the probe-matching persistence task. The probe latencies exhibit a clear sensitivity to target size (i.e., gap width) and target duration. In all cases examined, increasing either target size or target duration increases the resulting phenomenal persistence. These results replicate very closely recent findings of positive energy effects on the persistence estimates for briefly presented letters and pictures (Long, 1985). I believe that the most plausible and economical interpretation of these collective effects is in terms of a photoreceptor basis to the persistence. Positive energy effects upon the temporal extent of photoreceptor functioning are well known (e.g., Nunn \& Baylor, 1983; Whitten \& Brown, 1973a, 1973b). If visible persistence can be conceptualized as a phenomenal correlate of extended photoreceptor activity, the obtained positive-duration effects are to be expected. This point has been raised elsewhere in the interpretation of similar target energy effects on other types of persistence tasks (Sakitt, 1976; Sakitt \& Long, 1978, 1979a, 1979b).

The strong effect of increasing target size has also been reported in some previous work, although under a much narrower range of stimulus conditions (Long \& Beaton, 1980; Sakitt \& Long, 1978). Such a result is also consistent with an early locus to the persistence effects. Consider the well-known luminance-acuity tradeoff in vision. Large targets can be resolved under lower luminance levels than can small tar-

\section{HIGH PHOTOPIC BACKGROUND}

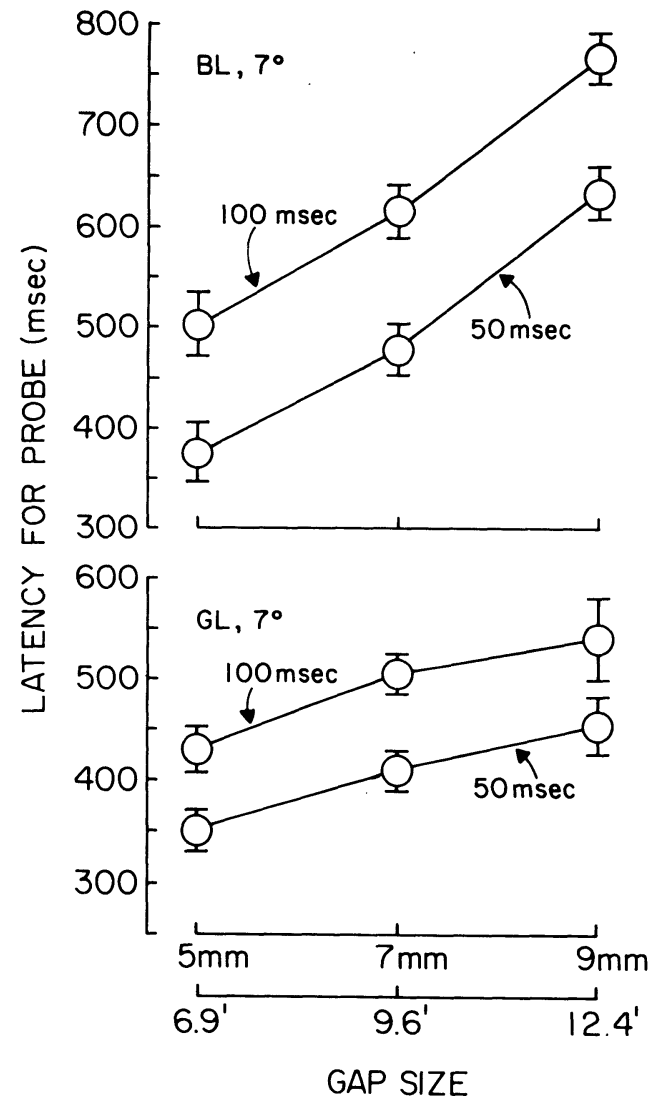

Figure 4. Mean persistence estimates for two observers as a function of gap size and target duration. Targets were presented $7^{\circ}$ from fixation and on a photopic background field. 


\section{LOW PHOTOPIC BACKGROUND}

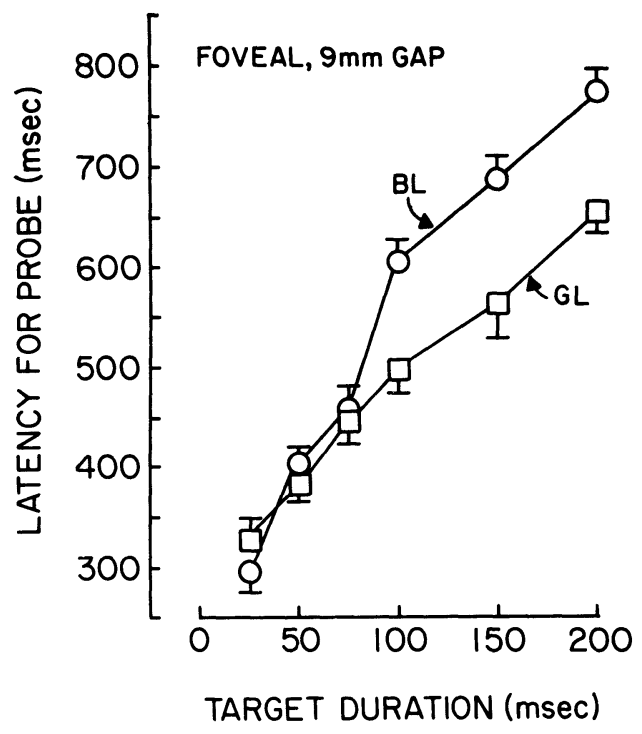

Figure 5. Mean persistence estimates for two observers as a function of target duration. Targets were presented foveally against a low photopic background field. The brackets around each point depict two standard errors above and below that value.

gets. If the fading visible trace of a target can be likened to a gradual reduction in target contrast, larger targets can be expected to remain visible when smaller targets are not. Hence, longer estimates of target visibility were expected for the larger gap widths in the present study.

It should be noted that both the target size and target duration effects of the present work are, on the face of it, in opposition to several previous studies. Other investigators, as well as this investigator using other tasks (Long \& Gildea, 1981; Long \& McCarthy, 1982), have occasionally reported inverse energy effects (Bowen, Pola, \& Matin, 1974; DiLollo, 1977) and inverse size effects on visual persistence (Bowling \& Lovegrove, 1980; Meyer \& Maguire, 1977, 1981). In fact, these inverse effects have typically been cited as critical evidence against a photoreceptor locus to persistence effects (DiLollo, 1980, 1984). However, the alternate interpretation proposed here is that these discrepant sets of results support the argument that different persistence tasks may be assessing different visual processes (see also Wilson, 1983). The strongest conclusion that is offered from the present work is that the visible persistence assessed by the probe-matching procedure exhibits characteristics consistent with a sensory-level persistence that is tied closely to photoreceptor sensitivities. Moreover, given the ranges of background levels, target durations, target luminances, and target locations examined in this work, attempts to attribute this "kind" of persistence to unusual or atypical viewing conditions (Coltheart, 1980; DiLollo, 1984) are no longer justifiable. At the same time, the acceptance of the present findings and the offered interpretation of them in no way precludes the existence of other, even very powerful, persistence effects in the visual system. The present work has sought to focus explicitly on a particular type of visible persistence task. Persistence tasks involving flickering (Lovegrove \& Meyer, 1984) or moving (Farrell, 1984) targets or even simply different task demands (Sakitt \& Long, 1979a) may involve other types of processes that also outlast the physical duration of the target. All of these possibilities must be considered.

\section{REFERENCES}

Adelson, E. H., \& Jonides, J. (1980). The psychophysics of iconic storage. Journal of Experimental Psychology: Human Perception \& Performance, 6, 486-493.

Aguilar, M., \& Stiles, W. S. (1954). Saturation of the rod mechanism of the retinal at high levels of stimulation. Optica Acta, 1, 59-65.
Bowen, R. W., Pola, J., \& Matin, L. (1974). Visual persistence: Effects of flash luminance, duration, and energy. Vision Research, 14, 295-303.

Bowling, A., \& Lovegrove, W. (1980). The effect of stimulus duration on the persistence of gratings. Perception \& Psychophysics, 27, 574-578.

Bowling, A., \& Lovegrove, W. (1982). Iconic memory: Fallacies persist (?). Perception \& Psychophysics, 31, 194-198.

BRINDLEY, G. S. (1962). Two new properties of foveal afterimages and a photochemical hypothesis to explain them. Journal of Physiological Psychology, 164, 168-179.

Brindley, G. S. (1963). Afterimages. Scientific American, 209, 84-93.

Coltheart, M. (1980). Iconic memory and visible persistence. Perception \& Psychophysics, 27, 183-228.

DiLollo, V. (1977). Temporal characteristics of iconic memory. $\mathrm{Na}$ ture, 267, 241-243.

DiLollo, V. (1980). Temporal integration in visual memory. Journal of Experimental Psychology: General, 109, 75-97.

DiLollo, V. (1984). On the relationship between stimulus intensity and duration of visible persistence. Journal of Experimental Psychology: Human Perception \& Performance, 10, 144-151.

FARRELL, J. E. (1984). Visible persistence of moving objects. Journal of Experimental Psychology: Human Perception \& Performance, 10, 502-511.

LoNG, G. M. (1985). Visual persistence from brief letters and pictures. Vision Research, 25, 887-892.

LONG, G. M., \& BeATON, R. J. (1980). The contribution of visual persistence to the perceived duration of brief targets. Perception \& Psychophysics, 28, 422-430.

LoNG, G. M., \& GILDEA, R. J. (1981). Latency for the perceived offset of brief target gratings. Vision Research, 21, 1395-1399.

LONG, G. M., \& MCCARTHY, P. R. (1982). Rod persistence on partialreport task with scotopic and photopic backgrounds. American Journal of Psychology, 95, 309-322.

LONG, G. M., \& SAKITT, B. (1980). The retinal basis of iconic memory: Eriksen \& Collins revisited. American Journal of Psychology, 93, 195-207.

Lovegrove, W. J., \& Meyer, G. E. (1984). Visible persistence as a function of spatial frequency, number of cycles and retinal area. $\mathrm{Vi}$ sion Research, 24, 255-260.

MEYer, G. E., \& MAGUiRE, W. M. (1977). Spatial frequency and the mediation of short-term visual storage. Science, 198, 524-525.

MEYer, G. E., \& MAGUiRE, W. M. (1981). Effects of spatial-frequency specific adaptation and target duration on visual persistence. Journal of Experimental Psychology: Human Perception \& Performance, 7 , 151-156.

NunN, B. J., \& BAYLOR, D. A. (1983). Visual transduction in single photoreceptors of the monkey Macaca fascicularis. In J. D. Mollon \& L. T. Sharpe (Eds.), Colour vision. New York: Academic Press.

SAKITt, B. (1976). Iconic memory. Psychological Review, 83, 257-276.

SAKITT, B., \& LoNG, G. M. (1978). Relative rod and cone contributions in iconic storage. Perception \& Psychophysics, 23, 527-536.

SAKITT, B., \& LoNG, G. M. (1979a). Cones determine subjective offset of a stimulus but rods determine total persistence. Vision Research, 19, 1439-1441.

SAKITT, B., \& LoNG, G. M. (1979b). Spare the rod and spoil the icon. Journal of Experimental Psychology: Human Perception \& Performance, 5, 19-30.

Whitten, D. N., \& Brown, K. T. (1973a). Slowed decay of the monkey's cone receptor potential by intense stimuli, and protection of this effect by light adaptation. Vision Research, 13, 1659-1667.

Whitten, D. N., \& Brown, K. T. (1973b). The time course of late receptor potentials from monkey cones and rods. Vision Research, 13, 101-135.

WiLSON, J. T. L. (1983). Effects of stimulus luminance and duration on responses to onset and offset. Vision Research, 23, 1699-1709.

(Manuscript received for publication April 29, 1985.) 